\title{
Study on Pore Structure and Sulfur Fixation Characteristics of Alkali Industrial Waste
}

\author{
Gaiju Zhao ${ }^{1,2, a}$, Fengjiao Yin ${ }^{2, b}, \mathrm{Jie} \mathrm{Li}^{2, \mathrm{c}}$ and Xuanyou $\mathrm{Li}^{2}$ \\ ${ }^{1}$ School of Environmental Sciences and Engineering, Shandong University, Jinan, Shandong , \\ 250100 China \\ ${ }^{2}$ Industrial Energy Conservation Research Center, Shandong Academy of Sciences, Jinan, \\ Shandong, 250103 China \\ a zhaogaiju@163.com, byfj62351240@163.com, ${ }^{\text {c }}$ jeff_lee@foxmail.com
}

Keywords: Alkali Industrial Waste; Pore Structure Characteristic; Sulfur Fixation Performance.

\begin{abstract}
Pore structure of experiment alkali waste were investigated by Mercury Porosimetry, the influence of pore structure characteristics on their sulfur fixation performance were discussed, it can be found that little pores make a significant contribution to calcium utilization in the initial stage of reaction and at lower temperature, while bigger pores take effect in the later stage and at higher temperature, the range of effective aperture are different at different temperature, which respectively are from $0.005 \mu \mathrm{m}$ to $0.02 \mu \mathrm{m}$ at temperature from $1123 \mathrm{~K}$ to $1223 \mathrm{~K}$ and from $0.2 \mu \mathrm{m}$ to $0.3 \mu \mathrm{m}$ at temperature from $1223 \mathrm{~K}$ to $1323 \mathrm{~K}$, the more pore in range of effective aperture, the better the sulfur fixation performance.
\end{abstract}

\section{Introduction}

At present, Coal-fired pollution is the focus of Chinese environmental pollution, in which controlling emissions of sulfur dioxide is an important element. With Chinese economic rapid development, a large number of industrial wastes are discharged and have caused serious environmental pollution. Some industrial waste contain a lot of alkaline substances, such as $\mathrm{CaO}$, $\mathrm{K}_{2} \mathrm{O}, \mathrm{Na}_{2} \mathrm{O}$, etc. and some elements, such as $\mathrm{Fe}, \mathrm{Mn}$, etc., $\mathrm{CaO}, \mathrm{K}_{2} \mathrm{O}, \mathrm{Na}_{2} \mathrm{O}$, etc. can directly react with $\mathrm{SO}_{2}$ and $\mathrm{Fe}, \mathrm{Mn}$, etc. can change the internal structure of $\mathrm{CaO}$, which make calcium sulfate reaction faster and calcium utilization ratio improved[1,2]. If alkaline industry wastes are selected as sulfur fixation agents, the purpose of waste governance waste and protecting environment can be achieved.

Sulfur fixation agents are generally porous solid material, their pore structure are different, their surface also are different, which directly affect the reaction rate, variety of kinetic parameters, such as reaction order, rate constant, activation properties, etc. [3-8]. How to objective and truly reflect pore structure of sulfur fixation agent is important to further enhance it's sulfur fixation efficiency. Since the 1970s, the influence of pore structure on sulfur fixation performance of shell, limestone and its products, such as $\mathrm{Ca}(\mathrm{OH})_{2}, \mathrm{CaO}$, etc were researched, a lot of quantitative evaluating indicator were formulated simultaneously. Alkaline industrial waste contains more $\mathrm{Fe}_{2} \mathrm{O}_{3}$ and $\mathrm{Al}_{2} \mathrm{O}_{3}$, during calcination and sulfur fixation process, they will react with $\mathrm{CaO}$ to produce $\mathrm{CaO} \cdot \mathrm{Al}_{2} \mathrm{O}_{3}, 3 \mathrm{CaO} \cdot$ $\mathrm{Al}_{2} \mathrm{O}_{3}, \mathrm{CaO} \cdot \mathrm{Fe}_{2} \mathrm{O}_{3}, 2 \mathrm{CaO} \cdot \mathrm{Fe}_{2} \mathrm{O}_{3}$, whose melting points are relatively low, this make sintering phenomenon occured and pore structure change of industrial waste entirely different from those of shells, limestone and its products. If indicators of limestone and shells are used to evaluate alkali industrial waste in specific experiments or engineering practices, mistakes or discrepancies with the actual situation are likely to occur. In this paper, microstructure and sulfur fixation mechanism of alkaline industrial wastes were analyzed, which provide theoretical basis for efficient use and modification of sulfur fixation agents. 


\section{Experiments Materials and Methods}

Experimental materials Three typical alkaline industrial wastes had been gathered from Shandong Province and made into experimental samples after drying, milling and screening. Their chemical composition analysis results were listed in table 1.

Table 1 Chemical composition of experimental materials (\%)

\begin{tabular}{|c|c|c|c|c|c|c|c|c|c|c|}
\hline \multirow{2}{*}{ Sample } & \multicolumn{10}{|c|}{ Chemical composition (\%) } \\
\cline { 2 - 13 } & $\mathrm{SiO}_{2}$ & $\mathrm{Al}_{2} \mathrm{O}_{3}$ & $\mathrm{Fe}_{2} \mathrm{O}_{3}$ & $\mathrm{CaO}$ & $\mathrm{MgO}$ & $\mathrm{SO}_{3}$ & $\mathrm{R}_{2} \mathrm{O}$ & $\mathrm{Cl}-$ & Loss & $\sum$ \\
\hline White clay & 10.7 & 0.86 & 0.21 & 48.5 & 1.8 & $/$ & 1.60 & 0.3 & 35.9 & 99.87 \\
\hline Carbide slag & 2.8 & 1.5 & 0.2 & 64.6 & 0.5 & $/$ & 1.3 & $/$ & 28.5 & 99.5 \\
\hline Red mud & 18.4 & 7.10 & 6.12 & 37.0 & 1.3 & 1.93 & 5.32 & $/$ & 19.1 & 96.27 \\
\hline Limestone & 2.1 & 0.46 & 0.2 & & 2.5 & $/$ & $/$ & $/$ & 43 & 99.86 \\
\hline
\end{tabular}

Experimental methods The sulfur fixation characteristics of experimental waste were studied by TGA/SDTA851e thermal analysis system in simulated flue gas $\left(0.245 \% \mathrm{Vol} \mathrm{SO}_{2}, 5 \% \mathrm{Vol} \mathrm{O}_{2}, 15 \%\right.$ Vol. $\mathrm{CO}_{2}$, the rest $\mathrm{N}_{2}$ ), The mass of samples are $10 \pm 0.2 \mathrm{mg}$, the medial diameter of sorbent particles were $0.2 \mathrm{~mm}$. heating rate of thermal analysis was $30^{\circ} \mathrm{C} / \mathrm{min}$. After the temperature was heated to set temperature, samples were added, mixed gas was passed into, whose flow was $120 \mathrm{ml} \cdot \mathrm{min}^{-1}$. The calcium utilization is calculated by the formula (1).

$$
x=\frac{\Delta m \cdot M_{\mathrm{CaO}}}{m_{0} \cdot W_{\mathrm{CaO}} \cdot M_{\mathrm{SO}_{3}}} \times 100 \%
$$

Where $m_{0}$ is the initial mass of sorbents, $\Delta m$ is the gain in weight after reaction, $M_{\mathrm{SO}_{3}}$ is the molar mass of $\mathrm{SO}_{3}, M_{\mathrm{CaO}}$ is the molar mass of $\mathrm{CaO}, x$ is calcium utilization of sorbent, whose value can reflect sulfur sorbent's absorption capacity and merits.

Microstructure of calcination products were investigated by Pore Master-60-type Porosity Analyzer and JEOL JSM-7600F Scan Electron Microscope.

\section{Results and discussion}

The pore structure characteristics of alkaline industrial waste Porosity, specific surface area, most probable pore size, and pore size distribution curve are shown in table 2 , table 3 , table 4 , figure 1 and figure 2 individually.

It can be known from table 2 and table 3 that porosity and specific surface area of calcined alkaline industrial waste at $1123 \mathrm{~K}$ are bigger than those of limestone, of which red mud is the largest one. With temperature increasing, porosity and specific surface area of calcined white clay and limestone ascend at $1223 \mathrm{~K}$ and descend at $1323 \mathrm{~K}$, while those of calcined carbide slag and red mud decrease, but the value of white clay and carbide slag still maintain larger at $1323 \mathrm{~K}$.

Table 2 Porosity of calcined samples ( $\%)$

\begin{tabular}{|c|c|c|c|}
\hline \multirow{2}{*}{ sample } & \multicolumn{3}{|c|}{ porosity (\%) } \\
\cline { 2 - 4 } & $1123 \mathrm{~K}$ & $1223 \mathrm{~K}$ & $1323 \mathrm{~K}$ \\
\hline White clay & 19.6648 & 25.2688 & 22.3296 \\
\hline Carbide slag & 21.7169 & 18.5493 & 15.1661 \\
\hline Red mud & 25.5493 & 17.1008 & 6.073 \\
\hline Limestone & 16.1745 & 22.1440 & 19.3544 \\
\hline
\end{tabular}


Table 3 Specific area of calcined samples $\left(\mathrm{m}^{2} / \mathrm{g}\right)$

\begin{tabular}{|c|c|c|c|}
\hline \multirow{2}{*}{ sample } & \multicolumn{3}{|c|}{ specific area $\left(\mathrm{m}^{2} / \mathrm{g}\right)$} \\
\cline { 2 - 4 } & $1123 \mathrm{~K}$ & $1223 \mathrm{~K}$ & $1323 \mathrm{~K}$ \\
\hline White clay & 8.2672 & 9.938 & 6.1477 \\
\hline Carbide slag & 8.6024 & 7.924 & 6.2689 \\
\hline Red mud & 9.6024 & 6.8949 & 2.9153 \\
\hline Limestone & 3.7148 & 6.3363 & 3.071 \\
\hline
\end{tabular}

Table 4 Most probable pore size of calcined samples $(\mu \mathrm{m})$

\begin{tabular}{|c|c|c|c|}
\hline \multirow{2}{*}{ Sample } & \multicolumn{3}{|c|}{ Most probable pore size $(\mu \mathrm{m})$} \\
\cline { 2 - 4 } & $1123 \mathrm{~K}$ & $1223 \mathrm{~K}$ & $1323 \mathrm{~K}$ \\
\hline White clay & $5.08 \mathrm{E}-03$ & $5.08 \mathrm{E}-03$ & 0.15 \\
\hline Carbide slag & $6.15 \mathrm{E}-03$ & $5.08 \mathrm{E}-03$ & 0.1 \\
\hline Red mud & $6.46 \mathrm{E}-03$ & 0.42 & 0.82 \\
\hline Limestone & 0.125 & $5.08 \mathrm{E}-03$ & 0.175 \\
\hline
\end{tabular}
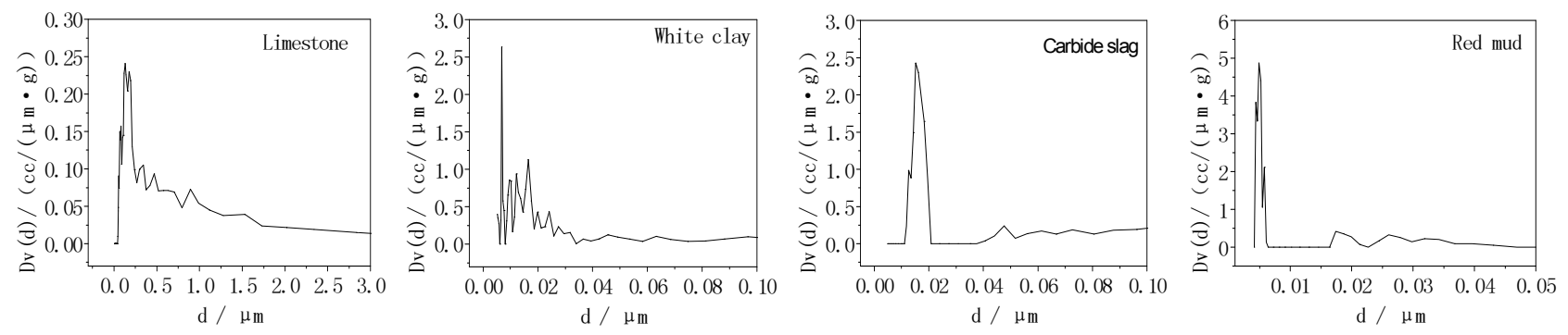

Figure 1. Pore size distribution curve of calcined samples at $1123 \mathrm{~K}$
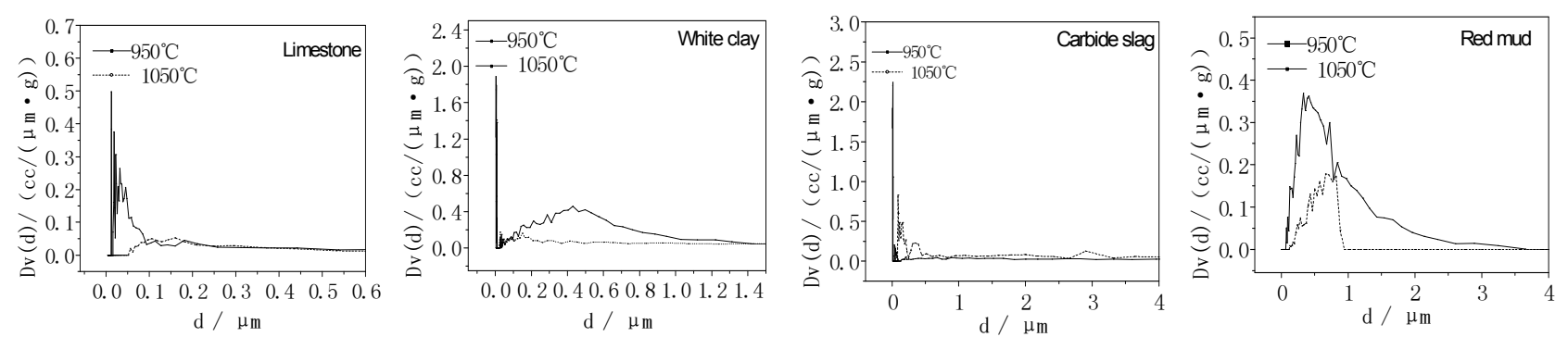

Figure 2. Pore size distribution curve of calcined samples at $1223 \mathrm{~K}$ and $1323 \mathrm{~K}$

It can be known from table 4, figure 1 and figure 2 that at $1123 \mathrm{~K}$, pore size of limestone focus on the range from $0.008 \mu \mathrm{m}$ to $2.5 \mu \mathrm{m}$, pore volume of the range pore sizes are about $0.67 \mathrm{ml} / \mathrm{g}$ and account for $82 \%$ of the total pore volume, the pore size of red mud is concentrated in the range from $0.004 \mu \mathrm{m}$ to $0.045 \mu \mathrm{m}$, pore volume of the range is respectively about $0.67 \mathrm{ml} / \mathrm{g}$ and account for $95 \%$ of total pore volume, pore size of white mud and carbide slag mainly are concentrated in the range from $0.0045 \mu \mathrm{m}$ to $0.3 \mu \mathrm{m}$, pore volume of the range are respectively $0.78 \mathrm{ml} / \mathrm{g}$ and $1.3345 \mathrm{ml} / \mathrm{g}$, the most probable pore size $d_{\text {op }}$ of soda residue is maximum, red mud's took the second place, carbide slag、white mud and limestone are a little smaller. When calcined temperature are increased to $1223 \mathrm{~K}$ and $1323 \mathrm{~K}$, the specific pore volume of range first increase and then decrease with the increase of calcined temperature, and the pore volume of limestone is lower, pore size become bigger obviously, the most probable pore size of white mud and limestone respectively increase to $0.15 \mu m$ and $0.175 \mu \mathrm{m}$ at $1323 \mathrm{~K}$, pores are mainly concentrated in the range from $0.005 \mu \mathrm{m}$ to $1 \mu \mathrm{m}$, Red mud has more $\mathrm{Fe}_{2} \mathrm{O}_{3}$ and $\mathrm{Al}_{2} \mathrm{O}_{3}$, during calcination process, they will react with $\mathrm{CaO}$ to generate $\mathrm{CaO} \cdot \mathrm{Al}_{2} \mathrm{O}_{3}$, $3 \mathrm{CaO} \cdot \mathrm{Al}_{2} \mathrm{O}_{3}, \mathrm{CaO} \cdot \mathrm{Fe}_{2} \mathrm{O}_{3}, 2 \mathrm{CaO} \cdot \mathrm{Fe}_{2} \mathrm{O}_{3}$, whose melting points are relatively lower, which make 
some holes plugged or molten pores formed, the most probable pore size are increased and almost all the pores in red mud are greater than $0.5 \mu \mathrm{m}$ at $1323 \mathrm{~K}$.

Sulfur fixation characteristics of alkali industrial waste Curves of Calcium utilization versus time of sorbents at different temperatures are shown in Figure 3.
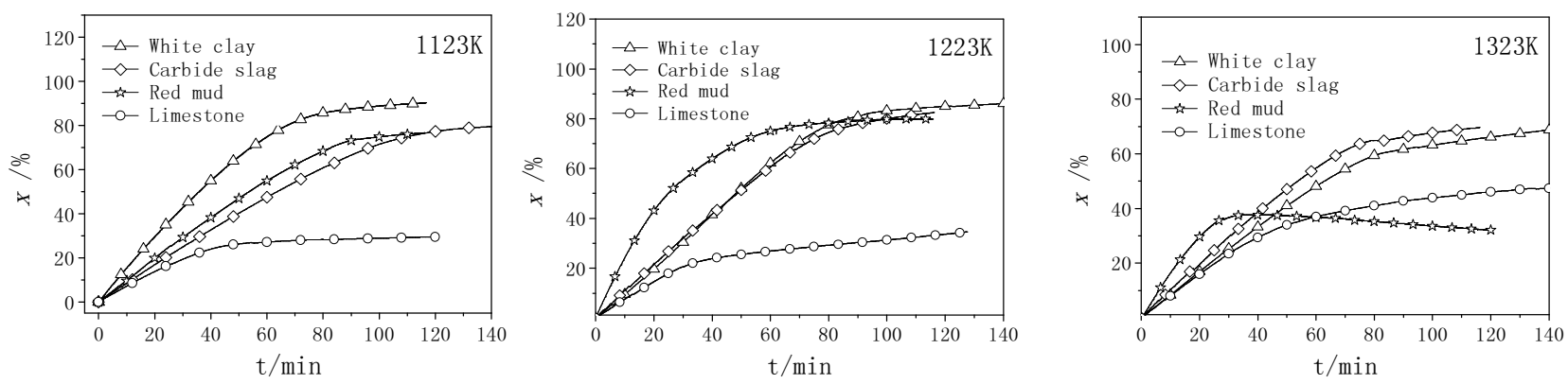

Figure 3. Calcium utilization versus time curves of sorbents at different temperatures

It can be known from figure 3 that at $1123 \mathrm{~K}$, initial sulfur fixation reaction rate of alkali industrial waste are larger than that of limestone, their higher sulfur fixation reaction rate can been maintained before 60 minutes, while that of limestone only lasted 40 minutes, eventual calcium utilization of alkali industrial waste are $87.96 \%, 82.48 \%$ and $76.1 \%$ respectively, while that of limestone only is $30.27 \%$, it can clearly be seen sulfur fixation performance of alkali industrial waste are better than that of limestone, in which red mud is best. At $1223 \mathrm{~K}$, initial sulfur fixation reaction rate of white clay, carbide slag and limestone increase, while that of red mud decrease. At 133K, initial sulfur fixation reaction rate of all test samples decrease, and sulfur fixation capacity of red mud loss earlier than that of limestone, while calcium utilization increment with time of white clay and carbide slag are faster than that of limestone, and those eventual calcium utilization are higher than that of limestone.

Influence analysis of Pore Structure Characteristics on Sulfur Fixation Performance of Alkali Industrial Waste It can be known from figure 1 that at $1123 \mathrm{~K}$, pore size of limestone focus on the range from $0.008 \mu \mathrm{m}$ to $2.5 \mu \mathrm{m}$ while the aperture range of alkali industrial waste are from 0.005 to $0.02 \mu \mathrm{m}$. Based on the diffusion mechanism criterion introduced in the literature [8], the diffusion duration of limestone should be longer than those of alkali industrial waste, but this is not true, this may be due to the grain of calcined limestone about $1 \mu \mathrm{m}$ while those of calcined industrial waste alkali only about $0.01 \mu \mathrm{m}$ as shown in figure 4 , which make active ingredient of sorbents with very wide diversification, the product layer relatively thin, product layer resistance low and calcium utilization rate maintaining growth in a long time.

Lastly, the sulfur fixation reaction is a structural change of gas and solid surface reaction of porous media, surface area size of sulfur fixation agent is also a very important factor to performance in addition to pore size. When the premise of gas diffusion met, reducing aperture and increasing reaction surface area can enhance sulfur fixation reaction rate and final calcium conversion rate, therefore, there should be a reasonable aperture distribution. Through analysing influence of pore structure characteristics on sulfur fixation performance of sorbents at $1223 \mathrm{~K}$ and $1323 \mathrm{~K}$, it can be found that the little pore make a significant contribution to calcium conversion rate in the initial stage of reaction while the bigger pore play a part in the later stage of reaction, the range of effective aperture at temperature ranged from $1123 \mathrm{~K}$ to $1223 \mathrm{~K}$ is from $0.005 \mu \mathrm{m}$ to $0.02 \mu \mathrm{m}$, calcined alkaline industrial waste owned more small holes in the range from $0.005 \mu \mathrm{m}$ to $0.02 \mu \mathrm{m}$, which result in bigger specific surface area, higher porosity, so initial calcium conversion rate of alkaline industrial waste are higher, pore size of limestone is larger, as a result its surface area is smaller and its initial calcium conversion rate is not high. The contribution of large holes gradually increase as the reaction, this mainly is because the smaller pores are filled for some time and the reaction is stopped, while 
there are enough space to ensure response to continue in the larger pores. Large holes in carbide slag account for the largest share, which make it's sulfur fixation reaction keep a low-speed growth in 120 mins.

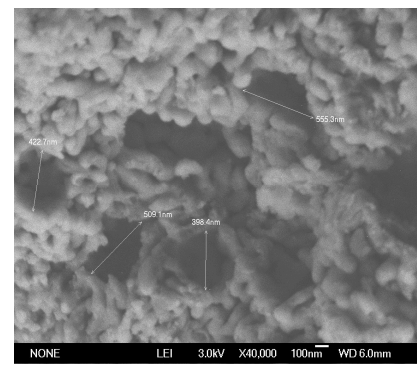

(a)

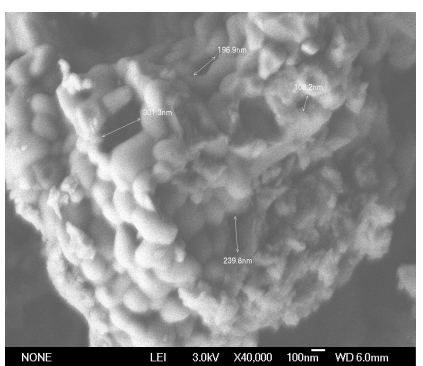

(b)

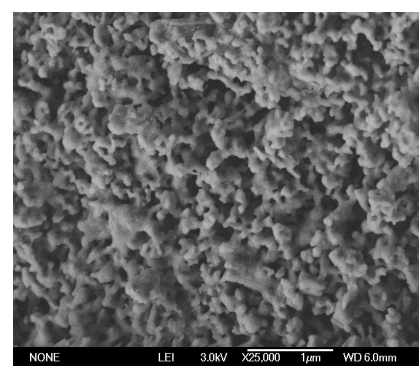

(c)

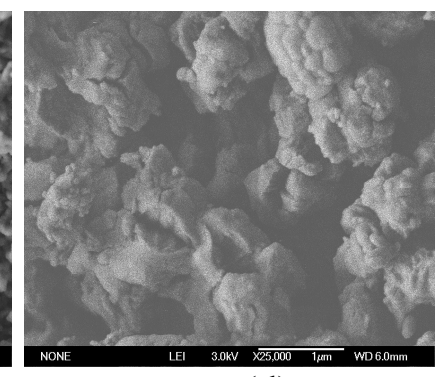

(d)

Figure 4. (a) SEM photogrphs of Carbide slag at 1123K, (b) SEM photogrphs of calcined White clay at $1123 \mathrm{~K}$, (c) SEM photogrphs of calcined Red mud at 1123K, (d) SEM photogrphs of calcined Limestone at $1123 \mathrm{~K}$.

The contribution of large holes gradually increase with reaction temperature increasing, this mainly is because at lower temperature, the chemical reaction rate and pore closing speed are relatively small, in other words, the increase in product thickness and diffusion resistance are slow, but when the temperature is high enough, that is, when chemical reaction rate is high enough, the surface of sorbent and $\mathrm{SO}_{2}$ react quickly, which make the most small hole quickly closed, $\mathrm{SO}_{2}$ and $\mathrm{O}_{2}$ are difficult to spread through the product layer and response to particles on the further surface, this lead to calcium conversion rate significantly decrease, while the larger pores ensure enough space to continue response after a longer period. Through analysing influence of pore structure characteristics on sulfur fixation performance of sorbents at $1223 \mathrm{~K}$ and $1323 \mathrm{~K}$, it can be found that the range of effective aperture is from $0.2 \mu \mathrm{m}$ to $0.3 \mu \mathrm{m}$ at temperature ranged from $1223 \mathrm{~K}$ to $1323 \mathrm{~K}$. as the result of sintering, pore structure of red mud is damaged, pore size mainly is bigger than $0.5 \mu \mathrm{m}$ at $1323 \mathrm{~K}$, the porosity $\varepsilon$, specific pore volume $V_{\mathrm{m}}$ and specific surface area $S_{\mathrm{m}}$ will be reduced evidently, so that it's calcium conversion rate are influenced evidently. Compared to red mud, white clay and carbide residue have less $\mathrm{Al}_{2} \mathrm{O}_{3}$ and $\mathrm{Fe}_{2} \mathrm{O}_{3}$, so sintering in their calcined samples are not as serious as that in red mud during calcining decomposition process, calcined white clay and carbide residue owned more holes in the range from $0.2 \mu \mathrm{m}$ to $0.3 \mu \mathrm{m}$ at temperature ranged from $1223 \mathrm{~K}$ to $1323 \mathrm{~K}$, So they possess bigger calcium conversion rate and good sulfur fixation characteristics.

\section{Conclusions}

The little pore make a significant contribution to calcium conversion rate in the initial stage and at lower temperature, while the bigger pore apparently take effect in the later stage and at higher temperature, the range of effective aperture are different at different temperature, which respectively are from $0.005 \mu \mathrm{m}$ to $0.02 \mu \mathrm{m}$ at temperature ranged from $1123 \mathrm{~K}$ to $1223 \mathrm{~K}$ and from $0.2 \mu \mathrm{m}$ to $0.3 \mu \mathrm{m}$ at temperature ranged from $1223 \mathrm{~K}$ to $1323 \mathrm{~K}$.

Calcined waste owned more small holes in the range of $0.005 \mu \mathrm{m}$ to $0.02 \mu \mathrm{m}$ at temperature ranged from $1123 \mathrm{~K}$ to $1223 \mathrm{~K}$, which result in more specific surface area, higher porosity, so calcium utilization of alkaline industrial waste are higher. With temperature increasing, as the result of sintering, pore structure of red mud is damaged, pore size mainly is bigger than $0.5 \mu \mathrm{m}$ at $1323 \mathrm{~K}$, the porosity $\varepsilon$, specific pore volume $V_{\mathrm{m}}$ and specific surface area $S_{\mathrm{m}}$ are reduced evidently, so that it's calcium conversion rate are influenced evidently at $1323 \mathrm{~K}$. Compared to red mud, sintering during calcining decomposition process of white clay and carbide residue are not serious because they have less $\mathrm{Al}_{2} \mathrm{O}_{3}$ and $\mathrm{Fe}_{2} \mathrm{O}_{3}$, they owned more holes in the range from $0.2 \mu \mathrm{m}$ to $0.3 \mu \mathrm{m}$, so they possess bigger calcium conversion rate and good sulfur fixation characteristics at higher temperature. 


\section{Acknowledgment}

This research was supported by Shandong Academy of Sciences Dr. Foundation and Shandong Science and Technology Projects (No. 2007GG20006013). The authors would like to thank clean-burning Laboratory of Shandong University, for providing thermal analysis TGA/SDTA851e and JEOL JSM-7600F Scan Electron Microscope.

\section{References}

[1] Zhou Junhu, Fan Haojie and Yao Qiang, Additives in $\mathrm{CaO}$ sulfation, Acta Scientiae Circumstantiae,vol.17(1997), pp. 284-288(In Chinese)

[2] Zhai Zhonghe, The establishment and comprehensive evaluation of the desulfurization feature index system of limestone, Systems Engineering-theory \&Practice, vol.18(1998), pp.130-134(In Chinese)

[3] Gullett B K, Bruce K R. Pore distribution changes of calcium based sorbents reacting with sulfur dioxide, AIChEJ, vol.3(1987), pp. 1719-1726

[4] Miao Mingfeng, Shen Xianglin, Modeling Investigation on the Characteristics of Pore Distributions of Calcium Based Sorbents, Journal of Southeast University(Natural Science Edition, vol.31(2001), pp.68-71(In Chinese)

[5] Mahuli S K, Agnihotri R, Shriniwas C, rt al. Pore-structure optimization of calcium carbonate for enhanced sulfation, AIChEJ, vol. 43(1997), pp. 2323-2335

[6] Ghosh-Dastidar A, Mahuli S K, Agninotri R, et al. Investigation of high reactivity calcium carbonate sorbent for enhanced SO2 capture. Ind Eng Chem Res, vol.35(1996), pp. 598-606

[7] Simons G A, Garman A R. Small pore closure and the deaction of the limestone sulfation reaction. AIChEJ, vol.32(1986), pp. 1491-1499

[8] Cheng Shiqing; Zhao Jianli; Li Guan-peng, Journal of Combustion Science and Technology, vol. 11(2005), pp.24-28. (In Chinese) 